Cahiers $d u$ MONDE RUSSE

\section{Cahiers du monde russe}

Russie - Empire russe - Union soviétique et États indépendants

$46 / 4 \mid 2005$

L'invention d'une politique humanitaire

\title{
Geoffrey Swain, Between Stalin and Hitler
}

\section{Catherine Gousseff}

\section{OpenEdition \\ Journals}

Édition électronique

URL : https://journals.openedition.org/monderusse/6627

DOI : $10.4000 /$ monderusse. 6627

ISSN : $1777-5388$

\section{Éditeur}

Éditions de l'EHESS

\section{Édition imprimée}

Date de publication : 1 décembre 2005

Pagination : 927-929

ISBN : 2-7132-2057-2

ISSN : $1252-6576$

\section{Référence électronique}

Catherine Gousseff, "Geoffrey Swain, Between Stalin and Hitler », Cahiers du monde russe [En ligne], 46/4 | 2005, mis en ligne le 29 juin 2009, consulté le 03 septembre 2022. URL : http://

journals.openedition.org/monderusse/6627; DOI : https://doi.org/10.4000/monderusse.6627

Ce document a été généré automatiquement le 3 septembre 2022

Tous droits réservés 


\title{
Geoffrey Swain, Between Stalin and Hitler
}

\author{
Catherine Gousseff
}

\section{RÉFÉRENCE}

Geoffrey SWAIN, Between Stalin and Hitler. Class War and Race War on the Dvina, 1940-46. Londres, New York : Routledge, 2004, 268 p.

1 La démarche est assurément digne d'intérêt : il s'agit de l'histoire de la Seconde Guerre mondiale dans la vaste zone du pacte Molotov-Ribbentrop successivement conquise par les Soviétiques, les nazis et à nouveau le grand voisin - abordée ici à travers l'étude de la région de Daugavpils (anciennement Dvinsk) au sud-est de la Lettonie. Un choix monographique justifié par la configuration particulière de ce territoire frontalier, marqué par l'importance et la diversité des minorités résidentes (juive, russe - dont une communauté notable de vieux-croyants installés de longue date -, polonaise, biélorusse). Située au cœur de la Latgale, Daugavpils ne comprenait que $35 \%$ de Lettons durant l'entre-deux-guerres. Outre son caractère multiethnique, la ville était devenue dans cette période le deuxième centre industriel du pays et ce, au sein d'une région essentiellement agricole peu dynamique. Diversité nationale, importants contrastes sociaux désignaient assez justement ce territoire pour soumettre à l'investigation les confrontations idéologiques entre nazisme et communisme, entre guerre de race et guerre de classes, qui se sont déroulées au cours de la Seconde Guerre mondiale à l'est de l'Europe.

2 La rétrospective proposée par G. Swain repose essentiellement sur la consultation d'archives (archives centrales de l'État soviétique et du parti communiste, de la République de Lettonie, de la région de Latgale et de la municipalité de Daugavpils, archives de l'occupation allemande) et sur la presse d'époque. De fait, la disparité entre la prépondérance des références à ces sources et le recours, exceptionnel, aux travaux publiés sur la période constitue une évidence. Que ressort-il de l'entreprise? Un exposé factuel de la guerre dans la région, à certains égards très précis (par exemple en ce qui 
concerne le génocide des Juifs), qui s'attache surtout aux faits et gestes des pouvoirs en place tout au long de la période considérée. On y voit comment se sont déroulés à l'échelle locale les grands scénarios, aujourd'hui bien connus, des annexions soviétiques et nazies sous des intensités, certes, variables. L'auteur souligne par exemple et à juste titre le caractère relativement mineur des déportations de juin 1941 (1 000 personnes) par rapport à d'autres régions particulièrement touchées par cette dernière grande opération répressive de l'avant-guerre soviétique. Il met également en évidence la spécificité de la politique allemande dans la région, qui visait à ménager la minorité russe tout en s'attaquant à la communauté des vieux-croyants (ces deux groupes ayant été finalement amalgamés dans la mise en œuvre des répressions).

3 Mais cette vaste histoire narrative, très minutieuse dans sa chronologie, est effectuée au détriment de toute véritable analyse des interactions entre les politiques conduites et les comportements de la population locale. Certes, des observations de caractère général ponctuent l'exposé: la politique instaurée par les nazis en 1941 consistant à faire apparaître le génocide des Juifs comme étant l'œuvre des « locaux » a bien conduit à une assistance lettonne aux massacres; de même, les déplacements forcés de population vers le Reich ont eut pour effet de grossir les rangs des partisans. De tels exemples pourraient être multipliés. Mais permettent-ils pour autant d'apprécier les degrés de collaboration et de résistance des populations soumises? En réalité, aucune tentative d'évaluation des mouvements d'adhésion ou de rejet n'est effectuée et ce, là même où la démarche serait la plus attendue, à savoir à travers la constitution de la Légion lettonne, des bataillons de volontaires russes, des services de police lettons, et, à l'inverse, des divers mouvements de résistance. Aucune donnée d'ensemble sur les formes de collaboration explicite ou sollicitée n'est fournie. Seuls apparaissent quelques chiffres au hasard des actions engagées, tandis que les plans répressifs concernant, par exemple, la population civile requise pour le travail forcé en Allemagne, sont, eux, numériquement très précis. La « seconde » période soviétique apparait, elle, plus documentée, notamment en ce qui concerne certaines caractéristiques des cadres du nouveau régime, en particulier leur nationalité : il apparait ainsi que les Lettons sont partout minoritaires - rejet massif du nouvel ordre soviétique par les Lettons ou imposition des éléments « allogènes »?

4 À la suite de cette dense rétrospective très informée, G. Swain livre en conclusion quelques éléments d'analyse qui reposent à la fois sur une perspective comparative avec des travaux concernant d'autres territoires (notamment la région de Vinnitsa, analysée par Amir Weiner ${ }^{1}$ ) et sur la comparaison entre les deux régimes soviétique et nazi. La réflexion menée sur le déroulement de la guerre en Ukraine et en Lettonie conduit l'auteur à quelques remarques d'ensemble sur la similitude des pratiques nazies (telle l'instrumentalisation faite de la terreur soviétique), et à insister sur quelques différences majeures à la fois dans les réformes agraires effectivement mises en œuvre en Lettonie et non en Ukraine, ainsi que dans les mouvements de résistance à la soviétisation, beaucoup plus radicaux parmi les nationalistes ukrainiens que chez les Lettons. S'agissant des deux totalitarismes, l'auteur constate que l'occupation allemande a entrainé des répressions plus importantes que le pouvoir soviétique et que la politique nazie a été plus incohérente que celle de Moscou. Pour étayer cette dernière conviction, G. Swain revient sur la contradiction entre la volonté allemande d'amadouer les minorités, en particulier la minorité russe, et la politique répressive qui a touché les Russes. Mais cette incohérence n'est-elle pas liée à la différence d'objectifs entre les dirigeants (allemands) et les exécutants (lettons) ? C'est en tout cas l'interrogation que le lecteur a en tête face à une telle assertion et qui le ramène à une question centrale que l'ouvrage, loin d'élucider, 
suscite en permanence. Quel est en effet l'enseignement des sources? Celles-ci permettent-elles de clarifier, dans une entreprise de micro-histoire, le comportement de la population locale? On ne peut que regretter le silence de G. Swain à ce propos. Ses affirmations relatives à «la faible minorité qui a participé aux guerres entre 1940 et 1946 » ne peuvent convaincre dans les dernières pages du livre après un exposé aussi allusif sur la période nazie, tant à l'échelle des administrations mises en place que des personnels investis dans ces appareils ou dans les organes policiers et militaires. En quoi réside l'analyse de la confrontation idéologique des deux totalitarismes invoquée par l'auteur, si, de fait, les acteurs, fussent-ils aussi des victimes, n'apparaissent qu'en pointillé?

\section{NOTES}

1. A. Weiner, Making Sense of War: The Second World War and the Fate of the Bolshevik Revolution, Princeton : Princeton University Press, 2001. 